\title{
Receiver System: Lessons Learned from Solar Two
}
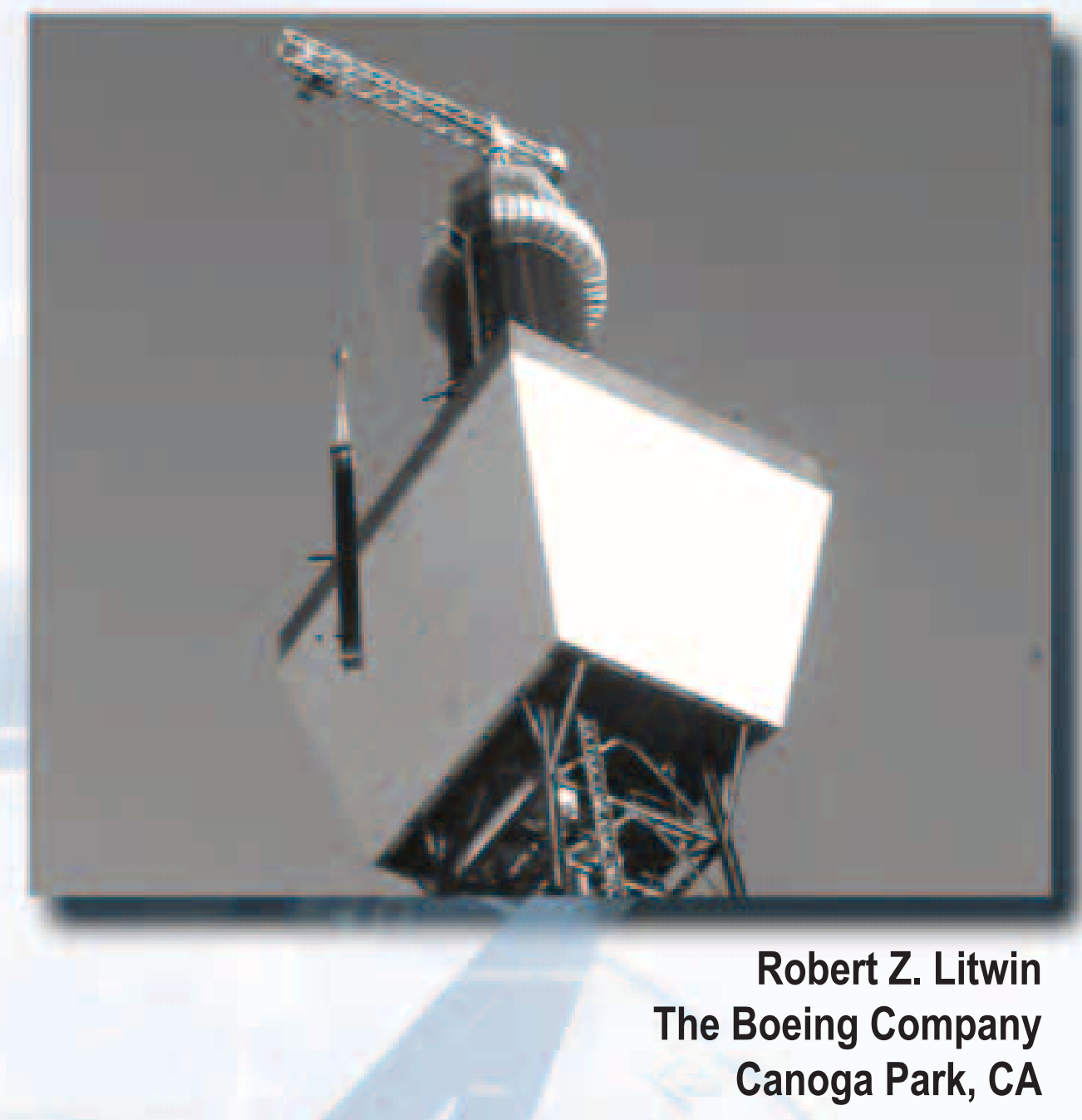
SAND2002-0084

Unlimited Release

Printed April 2002

\title{
Receiver System: Lessons Learned From Solar Two
}

\author{
Robert Z. Litwin \\ The Boeing Company \\ Canoga Park, CA
}

\begin{abstract}
The Boeing Company fabricated the Solar Two receiver as a subcontractor for the Solar Two project. The receiver absorbed sunlight reflected from the heliostat field. A molten-nitrate-salt heat transfer fluid was pumped from a storage tank at grade level, heated from 290 to $565^{\circ} \mathrm{C}$ by the receiver mounted on top of a tower, then flowed back down into another storage tank. To make electricity, the hot salt was pumped through a steam generator to produce steam that powered a conventional Rankine steam turbine/generator. This evaluation identifies the most significant Solar Two receiver system lessons learned from the Mechanical Design, Instrumentation and Control, Panel Fabrication, Site Construction, Receiver System Operation, and Management from the perspective of the receiver designer/manufacturer. The lessons learned on the receiver system described here consist of two parts: the Problem and one or more identified Solutions. The appendix summarizes an inspection of the advanced receiver panel developed by Boeing that was installed and operated in the Solar Two receiver.
\end{abstract}




\section{Table of Contents}

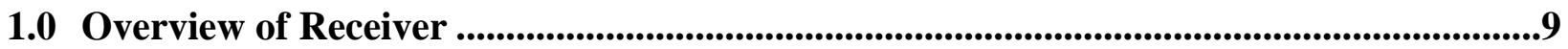

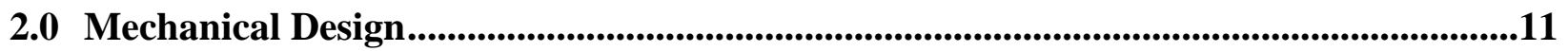

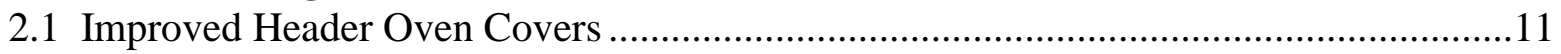

2.2 Elimination of Bypass Line Overheating …………...................................................12

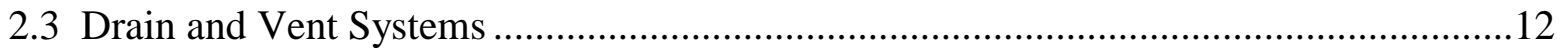

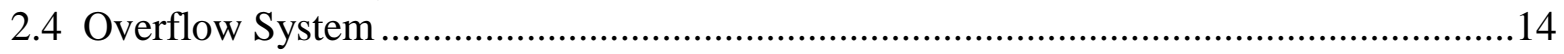

2.5 Receiver Outside Maintenance Access......................................................................

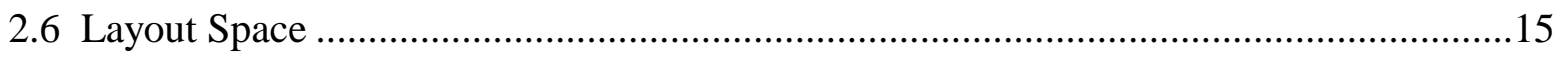

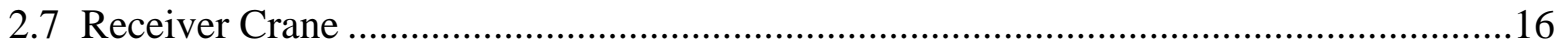

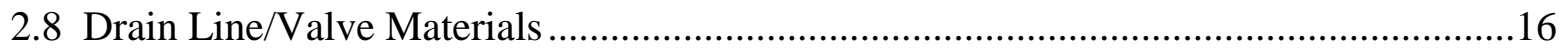

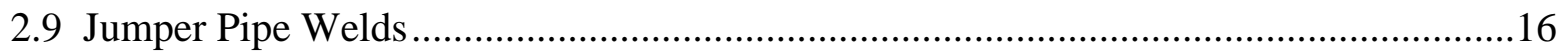

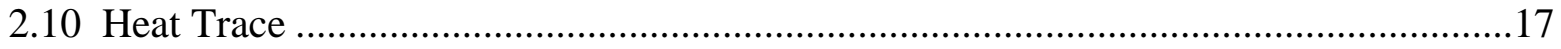

2.11 Outlet Vessel Transient Nozzle Analysis ..................................................................17

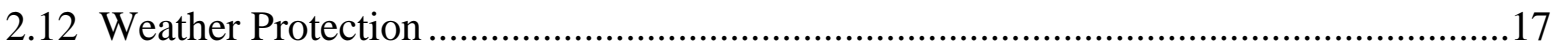

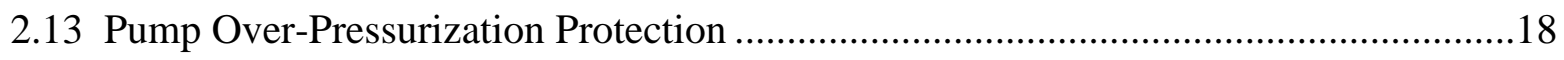

2.14 Provide a Debris Filter In the Receiver Inlet Line .......................................................18

2.15 Cold Leg Design Temperature …………...............................................................

2.16 Valve Shear Pins and Position Indicators.................................................................18

3.0 Instrumentation and Controls.........................................................................................................19

3.1 Heat Trace Display Screens........................................................................................19

3.2 Heliostat/Receiver Panel Temperature Combined Display Screens................................19

3.3 Fully Integrated Control System...............................................................................19

3.4 Automated Beam Characterization System (BCS) ....................................................19

3.5 Inlet and Outlet Vessel Level Instrument ....................................................................20

3.6 Thermocouple Failures and the Use of IR Technology to Determine Tube Wall

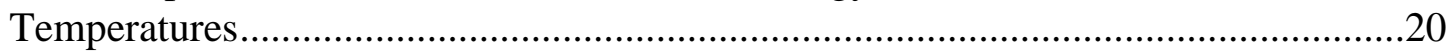

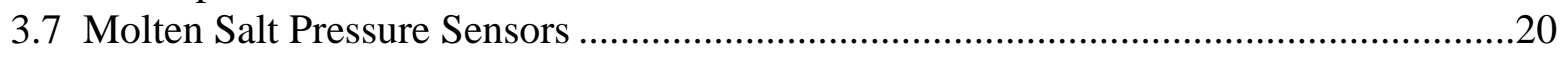

4.0 Receiver System Operation .................................................................................................................23

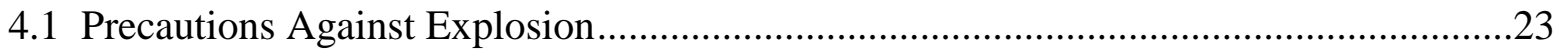

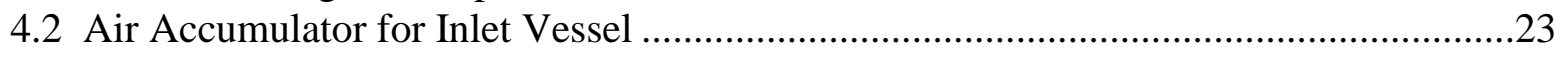

4.3 Potential For Chloride Stress Corrosion Cracking ……….............................................23

4.4 Thawing Frozen Panels .............................................................................................2

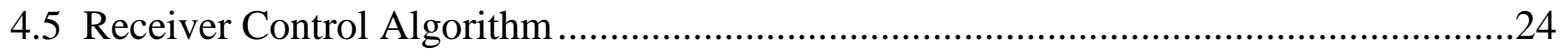

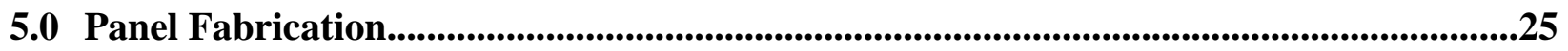

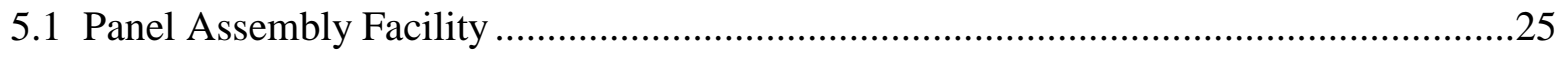

5.2 Panel Assembly Processes and Material Flow ………...................................................

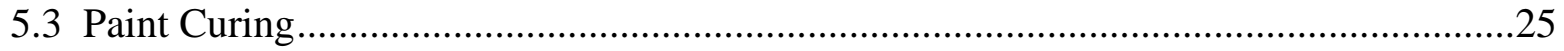

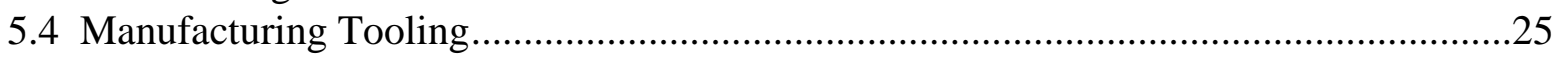

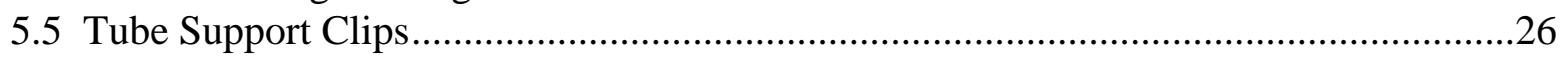

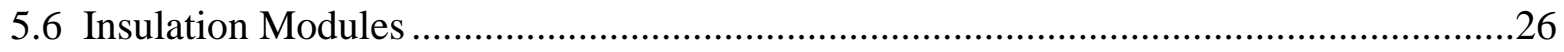

6.0 Site Construction ...............................................................................................................................27 


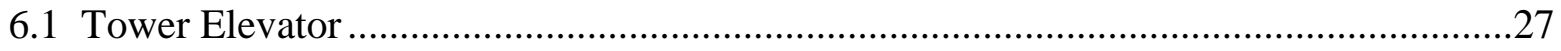

6.2 Construction Contractor Procurements ................................................................27

6.3 Weather Delays During Construction.........................................................................27

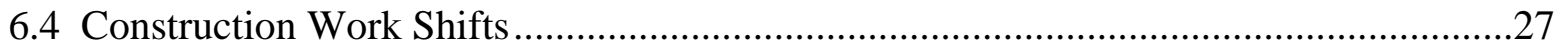

7.0 Management..........................................................................................................................29

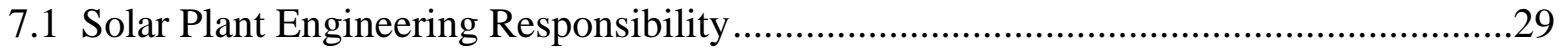

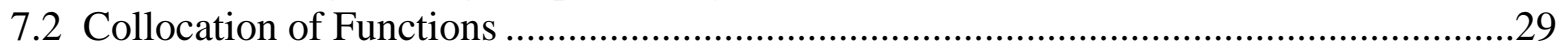

Appendix A: Solar Two Receiver Advanced Panel (W2) Final Inspection ............................30

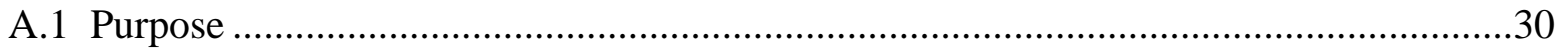

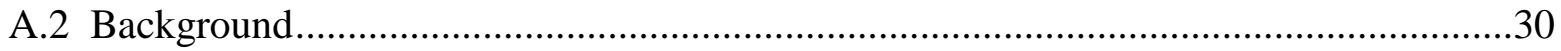

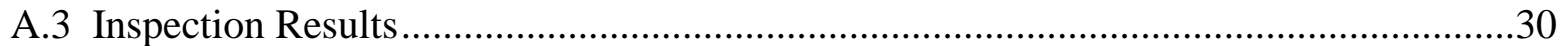

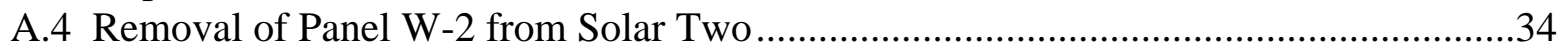

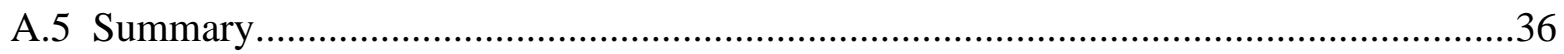

\section{Table of Figures}

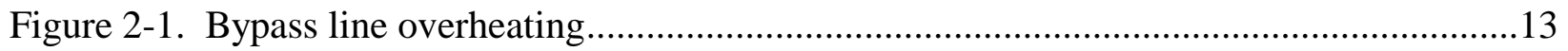

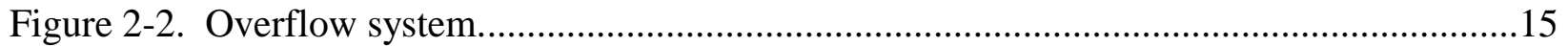

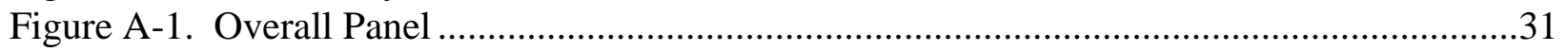

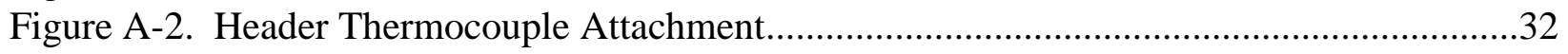

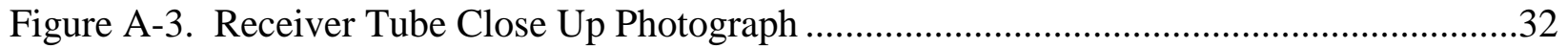

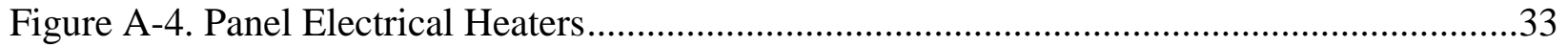

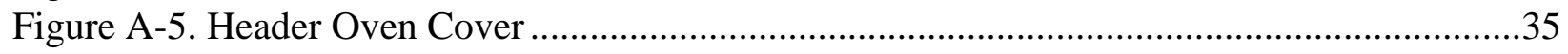




\section{Preface}

This evaluation identifies the most significant Solar Two Receiver System lessons learned from the Mechanical Design, Instrumentation and Control, Panel Fabrication, Site Construction, Receiver System Operation, and Management. The lessons learned described here consist of two parts: the Problem and one or more identified Solutions. This is not meant to be a "stand alone" document since the reader is assumed to have some familiarity with the Boeing Receiver System and the Solar Two facility. 


\subsection{Overview of Receiver}

The receiver was mounted in a tower approximately $76 \mathrm{~m}$ (250 feet) above the ground. It consisted of 24 panels, each comprising 32 individual tubes tangent to each other and running vertically for $15 \mathrm{~m}$ (50 feet). Each (flat) panel covered an arc of 15 degrees such that the 24panel receiver was able to absorb solar energy from every direction. During operation, sunlight was reflected by the heliostat field onto the receiver, which had molten salt flowing through it to absorb and transfer the heat to the thermal storage system. The salt flow rate was adjusted to produce a goal temperature of $565 \pm 14^{\circ} \mathrm{C}\left(1050 \pm 25^{\circ} \mathrm{F}\right)$. The molten salt came from the "cold" $\left(290^{\circ} \mathrm{C}\right)$ molten salt storage tank, entered the tower at the bottom, and was pumped up the riser to the receiver. Upon exiting the receiver, the hot $\left(565^{\circ} \mathrm{C}\right)$ molten salt went down the tower downcomer to be stored in the "hot" salt storage tank.

Salt was drained from receiver and the supply pipes during the night when there was no sunlight to heat it. The heat tracing was turned off, and the system came to ambient temperature. Thus, start-up the next day required heating the piping and receiver prior to flowing molten salt. The start-up heating utilized a combination of electrical heaters and a small number of heliostats on the empty receiver. The piping was heated first and salt flow was initiated up and down the tower using a bypass adjacent to the receiver until the receiver was at temperature, at which point molten salt flow through the receiver was initiated. 


\subsection{Mechanical Design}

\subsection{Improved Header Oven Covers}

Problem: The receiver panel header oven cover fabrication cost was significant $(\sim 240 \mathrm{~K})$ and the covers were damaged due to "spillage" from poor heliostat aiming. This spillage caused distortion or warping of the oven covers and resulted in an increased gap between the cover and the receiver tubes. The oven covers were cantilevered and connected at one end to each panel strong back. If overheated sufficiently, these covers thermally grow and experience plastic strain. A ratcheting effect occurred upon cooldown that continually increased the gap between the free end of the covers and the tubes. During windy conditions (as low as about $30 \mathrm{~km} / \mathrm{hr}(20 \mathrm{mph})$ ), this gap allowed ambient air to enter the oven cover system and made it difficult to electrically preheat the headers to their required $230+{ }^{\circ} \mathrm{C}\left(450^{\circ} \mathrm{F}\right)$ prior to salt fill. This was most pronounced with the lower oven covers, as indicated by oven thermocouples. "Bumpers" were designed and added to both the lower and upper oven covers in an attempt to close the gap between the oven covers and the tube surface. This was initially successful; however, over time the oven covers continued to ratchet away from the tube plane due to excess spillage and temperature and the gap continued to open. The placement of these bumpers also blocked approximately $5 \%$ of the absorber tube surface area. However, this was overcome by bringing together the heliostat aim points. The lower tube support was located at the elevation of the lower oven cover gap. This was thought to act as a heat sink, further creating a "cold" region on the tubing. In the original panel design, the tubes stood approximately $12 \mathrm{~mm}(1 / 2 \mathrm{inch})$ from the panel insulation. Wind normal to the panel could flow around the tubes and impinge on the insulation. From there, it could flow behind the tubes and vertically down into the lower oven cover region or up into the upper oven cover region. This also added to the header oven cooling effect and made them more difficult to electrically preheat.. An IR camera located in the heliostat field was utilized and focused on the tube surfaces. It indicated that several tubes were occasionally frozen during fill and low heliostat preheat power had to be held on the panels longer than desired in order for the "flow blockage" to clear prior to power operation. It was never completely resolved whether the tube freezing occurred during the previous receiver drain or the receiver fill operation, but it was possible for it to occur in either.

The oven cover area just above and below the active absorber panels are subjected to significant solar flux. If spillage is maintained to design values, this flux can be accommodated. However, under off-normal flux conditions, heat shield integrity can beaffected.

Solution: A solution is to maintain the basic oven cover design but to redesign the oven cover seal region by using seal compressive force. Wear on the tubes (due to sliding) should be acceptable. Internal vertical baffles can also be utilized to increase pressure drop between

adjacent oven covers.. A final acceptable concept will be selected early in the receiver system design. 


\subsection{Elimination of Bypass Line Overheating}

Problem: During operation, hot outlet salt in the downcomer would mix with stagnant cold salt in the bypass line, causing elevated temperatures to occur in the carbon steel bypass line and in the carbon steel drain line. This overheating was caused by thermal siphoning. The problem was solved with salt attemperation by allowing a small stream of cold salt to constantly flow through the bypass valve and down the bypass line. This resulted in a small $3-6^{\circ} \mathrm{C}\left(5-10^{\circ} \mathrm{F}\right)$ drop in the downcomer temperature that was accommodated by raising the receiver outlet temperature about $6^{\circ} \mathrm{C}\left(10^{\circ} \mathrm{F}\right)$ to $571^{\circ} \mathrm{C}\left(1060^{\circ} \mathrm{F}\right)$ to achieve the nominal outlet temperature of $565^{\circ} \mathrm{C}\left(1050^{\circ} \mathrm{F}\right)$.

Solution: Several solutions have been evaluated, including: 1) changing the bypass line slope so that it rises towards the downcomer. This will prevent the capability of completely draining the bypass line and will result in an undrainable heel in the inlet vessel; however, this is considered acceptable. Salt will be allowed to freeze in the vessel, since it will only be a few inches deep. Prior to establishing bypass flow, the electrical heat trace will be activated; 2) fabrication of the bypass line, bypass valve, and drain line from stainless steel (instead of carbon steel) to accommodate the elevated temperature; 3) installation of a check valve in the bypass line to prevent thermal siphoning; 4) maintaining a cold bypass flow to attemperate the bypass line, similar to Solar Two; and 5) move the bypass valve to the right of the fill and drain line and fabricate the valve from stainless steel. Options 1) and 5) are the recommended solutions and will be further evaluated early in the receiver system design (see Figure 2-1).

\subsection{Drain and Vent Systems}

Problem: Several improvements in valve selection are required.

1) Ball-type valves were used for vent and drain valves. Experience indicated these valves did not operate satisfactorily in salt. Excessive friction between the ball and the seat and solid debris in the salt scratched the sealing surfaces and caused shear pin failure and loss of valve operation. The congested valve location and configuration made shear pin replacement very difficult.

2) The compact drain valve configuration, although desirable in receiver system layout, overheated the valve stem seal because of its close proximity to the valve body. 


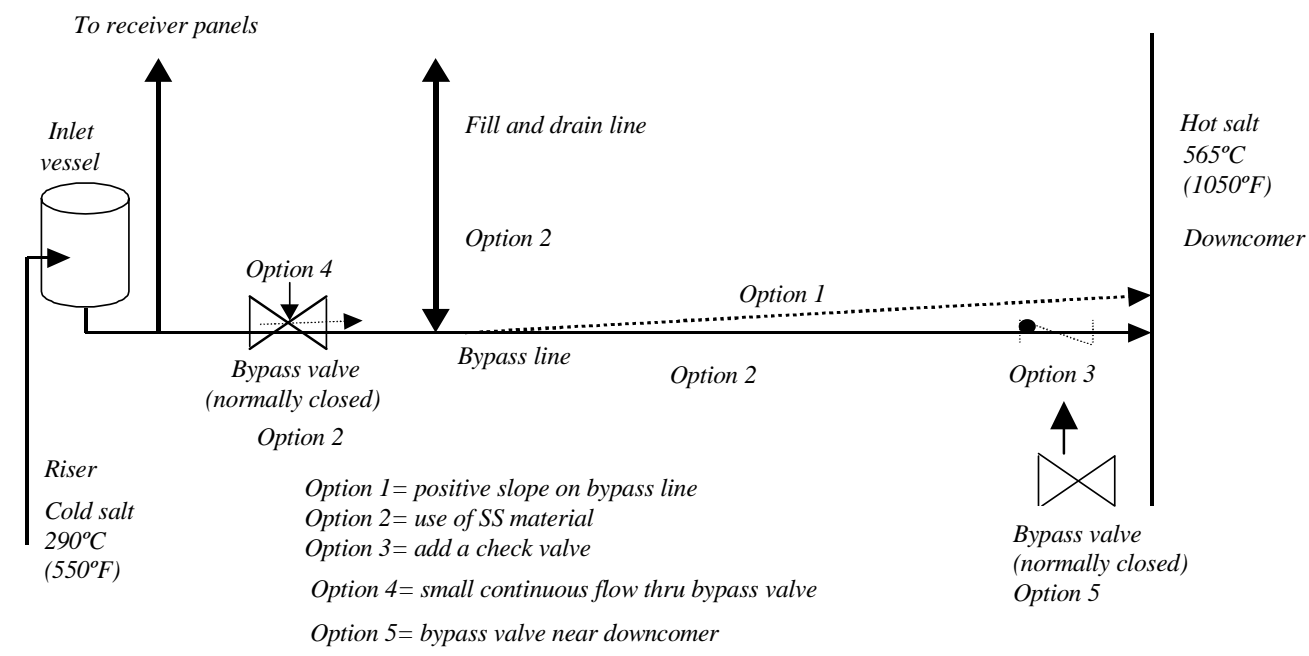

Figure 2-1. Bypass line overheating

3) Drain system piping was sized for a 60 -sec receiver drain. This is now considered too slow and should be resized for a 10-20 sec drain. The concern is that salt freezing in the panels may occur if the drain is too slow, even with post-heat heliostats on the receiver during the drain.

4) The vent piping was too congested and was difficult to install and insulate.

5) The use of orifi in the vent system reduced the number of vent valves but created an anticipated small amount of bypass flow that must be evaluated further. The cool, bypassed flow rejoined the main flow stream and gave an unexpected low local temperature indication. Overall receiver efficiency may be slightly affected.

\section{Solution:}

1) In Solar Two, the 12 ball-type drain valves and two ball-type vent valves were all replaced with gate-type valves that operated nominally. Gate valves have less frictional resistance and are not as sensitive to solid debris in the salt. Shear pins or gearing were never broken on the latter. Drain valves were fabricated from carbon steel, which is acceptable, if they do not experience internal leakage. From Solar Two operation, it was believed that these gate valves were leak-free.

2) Stem seals were located further from the valve body and could be maintained at acceptably low temperatures.

3) Larger-diameter drain lines and full ported gate-type drain valves should be utilized so that flow is not restricted. The faster fill/drain capability in the next design will support a more even flood fill. In Solar Two, it was believed that panel inlet lines filled before the panels during a flood fill because flow was under less resistance. This in turn caused salt spillover from the top in the first panels of both circuits. With spillover, there is a higher potential to 
trap air in the circuits during fill. With adequately large fill/drain lines, flood fill from the bottom of the panels should be utilized as the reference fill procedure; however, serpentine fill can also be utilized. Flood fill best assures the elimination of air from the system, as all panels are filled together in parallel, rather than in series.

4) Vent piping layout should be revised for more access. Piping should be spread vertically for more expansion space and installation space. Vent valves and lines in Solar Two were fabricated from stainless steel because of the potential for high temperatures.

5) Vent system orifi will be evaluated against the use of an increased number of vent valves. Orifi offer a much more reliable passive system if it is determined that receiver thermal performance is not adversely affected.

\subsection{Overflow System}

Problem: An overflow system is required to prevent the potential discharge of salt from the inlet and outlet vessels due to overfill. Overfill is possible because these vessels are vented to the atmosphere. In Solar Two, overflow piping and an overflow "canon" was provided to direct salt off the tower and allow it to freeze (prill) and cool in the air before it reached the ground. However, the potential of falling salt (solid or molten) requires an exclusion zone at the bottom of the receiver tower that restricts maintenance, complicates plant operation, compromises plant safety, and requires cleanup.

Solution: The overflow from the vessels could be directed to the thermal storage hot or cold tanks through carbon steel, $20 \mathrm{~cm}$ (8 inch) schedule-5 piping (or similar piping), with minimum insulation $(\sim 3 \mathrm{~cm})$ and no heat trace. The tank will have a slip joint nozzle to accommodate overflow piping thermal expansion or the overflow piping will incorporate expansion loops. The overflow piping shall be equipped with several thermocouples to indicate when overflow has occurred. Upon a high-temperature indication, removable/replaceable sections of overflow piping shall be inspected and should be capable of clean out in the event of frozen salt blockage. See Figure 2-2. Another option is a small overflow tank on the receiver deck sized to hold about one minute of flow. In the event of an overflow, a valve from this small tank would open allowing flow to enter the downcomer. This approach is less desirable because attaching a "cold" line to the $565^{\circ} \mathrm{C}\left(1050^{\circ} \mathrm{F}\right)$ downcomer may be difficult due to the large thermal growth of the downcomer and the addition of an active valve. Both concepts will be evaluated further when a decision to delete the downcomer drag valves is finalized.

\subsection{Receiver Outside Maintenance Access}

Problem: Periodically, it is desirable to access the receiver absorber surface to inspect or paint the tubes. Access is also required to remove and replace a tube in the event of a leak. Even in low wind conditions $(\sim 25 \mathrm{~km} / \mathrm{hr}(15 \mathrm{mph}))$, access to the receiver outside surface was difficult 


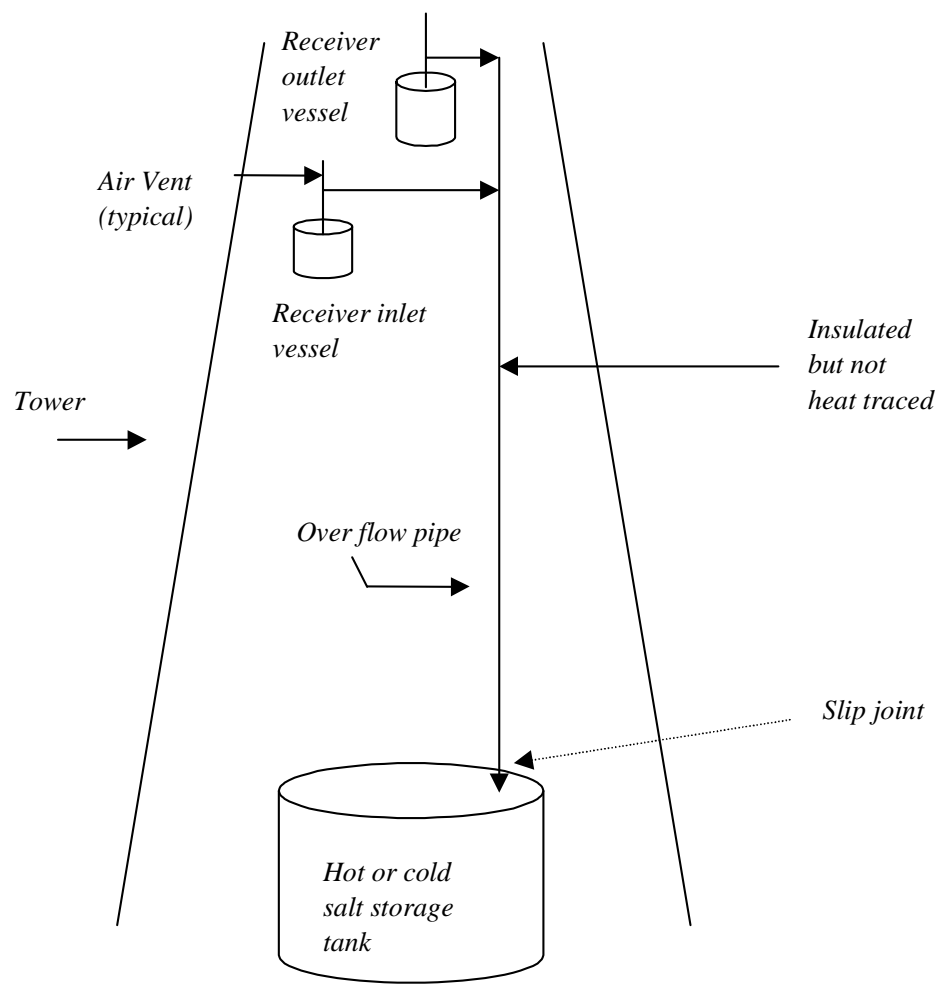

Figure 2-2. Overflow system.

due to the instability of the man-lift, which was suspended by cables from the crane. A safer and more stable method is required.

Solution: Improved maintenance will be inherently achieved if the receiver headers are turned inward, as described in Section 2.1. With this accomplished, the need to access the outside receiver surface will be greatly reduced. Tube replacement welding would be performed within the receiver and outside access would be limited to withdrawal and insertion of the replacement tubes and periodic painting of the Pyromark surface. To further improve maintenance, a more stable man-lift system should be provided that is equipped with bumpers so that it is capable of being held stable against the receiver tube outer surface without damaging the surface finish. This man-lift system could be a basket suspended from the overhead crane (separate from the crane hook but mounted on the trolley) or a separate scissors lift from the receiver deck.

\subsection{Layout Space}

Problem: The Solar Two receiver was restricted to the existing support structure diameter that was built for Solar One in order to reduce costs. This caused a congested internal volume that was difficult for routing pipe and components and was too cramped to easily maintain the receiver system. Many piping layout iterations were required because of the large thermal expansion experienced over large temperature swings from ambient to $565^{\circ} \mathrm{C}\left(1050^{\circ} \mathrm{F}\right)$ and the relatively confined space available for pipe routing. 
Solution: Follow-on, larger receivers $\left(120 \mathrm{MW}_{\mathrm{t}}\right.$ ) will require a larger diameters (about $9.0 \mathrm{~m}$ $(30 \mathrm{ft})$ versus $5.0 \mathrm{~m}(16.5 \mathrm{ft})$ for Solar Two $\left(42 \mathrm{MW}_{\mathrm{t}}\right)$ ). This still may be inadequate because of increased pipe size. If necessary, the receiver diameter could be increased slightly in order to facilitate the layout. Vent system piping would be laid out more vertically for thermal expansion and access. Design should proceed from the start with a pipe stress analyst and tower structural analyst working together with the system designer to lay out the piping. Room for personnel access with ladders and decking must also be provided from the start. Insulation on piping and components should be included when performing an evaluation of available space.

\subsection{Receiver Crane}

Problem: Due to heliostat spillage and natural convection-driven heat off the receiver surface, the maintenance crane was subjected to high temperatures that dried out grease, damaged electronics and switches, and damaged rubber components, resulting in the need for periodic repair and reduced availability of the crane. Crane vertical speed was too slow, resulting in lost efficiency when lifting parts and components from the ground.

Solution: Provide a collapsible (stow-away) capability or additional thermal shielding so the crane is not subjected to stray flux. The first approach is preferred. Provide higher speed gearing for vertical travel. Provide a cage to lift tools and equipment.

\subsection{Drain Line/Valve Materials}

Problem: During "hot" drains and in the event of leakage through drain valves during receiver operation, some of the drain lines and the drain valves themselves were subjected to temperatures greater than normally acceptable for carbon steel material.

Solution: If hot drains are a system requirement, stainless-steel material will be used. The use of gate valves should preclude valve leakage. Perform a cost trade analysis to determine if these components should be fabricated out of stainless steel to survive valve leakage.

\subsection{Jumper Pipe Welds}

Problem: Each jumper pipe required nine welds, which was time-consuming and expensive to fabricate. Field measurements were made and welding was done in a shop. Wild ends were utilized for final fit-up in the field.

Solution: Investigate a new design that uses bent pipe and fewer welds to reduce cost and installation time. 


\subsection{Heat Trace}

Problem: Heat trace is expensive to install and requires special attention to details to obtain uniform heating. It is difficult to place control thermocouples in the right place so that a heating zone does not result in underheating or overheating the pipe or component. Provide adequate installed spare heaters.

Solution: Consider using tubular heaters in place of MI cable on larger piping and large components. The tubular heaters can deliver 650 watts per $\mathrm{m}$ ( 200 watts per linear foot) versus $160 \mathrm{~W} / \mathrm{m}(50 \mathrm{~W} / \mathrm{ft})$ for MI cable. Thus, a significant savings in the total length of heaters would be achieved. Difficulty in bending the tubular heaters must be evaluated against the reduced lengths required. Uniform application and adequate serpentine bending of the heaters must be achieved so that overheating/underheating is avoided and thermal expansion is accommodated. Control thermocouples should be located carefully to indicate the coldest segment of piping and assure adequate heating. A heat trace construction specification must be prepared with easy-tofollow drawings. Construction personnel prefer sketches rather than written procedures when it comes to installing heat trace. Installed spare heaters are essential, especially on components like valves that are difficult to heat trace and accurately determine heat loss.

\subsection{Outlet Vessel Transient Nozzle Analysis}

Problem: The outlet vessel inlet nozzles were subject to severe thermal transients due to rapid changes in molten salt temperature. These nozzles required careful analyses and were difficult to design to meet the design transients.

Solution: It is recommended that Boeing design and analyze these nozzles based upon the experience learned from Solar Two. The remainder of the detailed vessel design can be subcontracted to a competent vessel designer after Boeing completes the conceptual design.

\subsection{Weather Protection}

Problem: Water intrusion due to rain can damage electronics. Wind inside the receiver can cause cooling of salt lines and increases heat trace requirements.

Solution: Provide a weather-proof roof over the receiver core to preclude rain water that could damage electrical instrumentation and cable. Provide drain holes on junction boxes, termination boxes, and instrumentation enclosures as a backup means of minimizing water damage in the event of water intrusion. Maintain a closed vertical receiver system to preclude the effects of wind. Allow natural draft airflow from below the absorber panels (like Solar Two) and out an installed vent with a rain hat at the top of the receiver to remove heat buildup. Maintain the capability to include a booster suction fan in the vent, if required. Monitor interior receiver temperatures with several vertically located thermocouples. Temperatures should be maintained below about $50^{\circ} \mathrm{C}\left(120^{\circ} \mathrm{F}\right.$ ) (or below instrumentation maximum rated temperatures) during operation for instrumentation protection. 


\subsection{Pump Over-Pressurization Protection}

Problem: The cold salt pump characteristics allow the dead head pump pressure to increase beyond the design pressure of the inlet vessel and the receiver panels. Receiver over-pressure protection was provided by installing of a bypass line, pressure relief valves, and high-pressure shutoff switches.

Solution: A safer, more inherent solution is to select a cold salt pump with a flat pump curve that cannot develop dead end pressures above receiver design values.

\subsection{Provide a Debris Filter In the Receiver Inlet Line}

Problem: In Solar Two, solid debris from a salt line on the ground was entrained in the flowing salt and plugged several receiver tubes. Debris was created by an over-temperature trace-heated salt line that physically disintegrated the carbon steel pipe. A filter was later placed in the inlet lines to the receiver system.

Solution: Incorporate a removable metal screen filter (approximate $3 \mathrm{~mm}(1 / 8 \mathrm{inch}) \mathrm{mesh})$ in the receiver inlet line to protect the receiver system from foreign debris that could block flow or interfere with valve operation. Provide delta pressure instrumentation across the filter to monitor its condition.

\subsection{Cold Leg Design Temperature}

Problem: In some instances, system cold leg salt temperatures exceeded the nominal value of $290^{\circ} \mathrm{C}\left(550^{\circ} \mathrm{F}\right)$. This occurred because operators did not want to put warm salt $\left(315-370^{\circ} \mathrm{C}(600-\right.$ $\left.700^{\circ} \mathrm{F}\right)$ ) into the hot tank and degrade the hot tank's thermal value.

Solution: Provide a receiver and inlet vessel capable of accommodating $370^{\circ} \mathrm{C}\left(700^{\circ} \mathrm{F}\right)$ cold salt (for a limited amount of time) to give the plant more operational flexibility.

\subsection{Valve Shear Pins and Position Indicators}

Problem: Position indicators that were located on the drive side of a shear pin falsely indicated drain valve position when the pin was sheared.

Solution: Position indicators should be located on the shaft connected to the sealing surface (gate or globe), not on the drive-side shaft. 


\section{Instrumentation and Controls}

\subsection{Heat Trace Display Screens}

Problem: The heat trace system was displayed on a dedicated screen and not well-integrated with the rest of the plant. Preheat temperatures that were below or above nominal range were not readily displayed to the operator. Personnel had to scroll through several dozen screens to manually confirm proper heat trace temperatures prior to salt fill.

Solution: Provide a real-time automatic function that summarizes all preheat zones that are not within the acceptable temperature range. As acceptable temperatures are reached, the list would be automatically updated and reduced. A single caution/warning signal should also be automatically relayed to the operator if all the heat trace zones are not within allowable limits.

\subsection{Heliostat/Receiver Panel Temperature Combined Display Screens}

Problem: These screens were very comprehensive; they were integrated to show receiver system temperatures and heliostats status and should be considered for the next plant. However, clearer caution/warning information should be displayed when out-of-specification receiver temperature conditions exist. For many weeks, north-west receiver panels were over-fluxed without a warning generated and without operators noticing high temperatures.

Solution: Indicate out-of-specification conditions, such as panel dry preheat temperatures, panel-to-panel delta temperatures with flowing salt, and salt-filled panel temperature with a color code and relay a caution/warning to the operator.

\subsection{Fully Integrated Control System}

Problem: Solar Two utilized separate systems for turbine generator operation, heat trace control, heliostat control, and molten salt/steam systems. Although these systems were set up to communicate with each other, on many occasions this was not reliable. This increased operator inefficiency, requiring three or four operators to do the job of one.

Solution: Design a fully-integrated control system with all information available to all consoles. This would greatly reduce operator costs and improve reliability.

\subsection{Automated Beam Characterization System (BCS)}

Problem: Heliostat aiming and correction was performed manually at Solar Two, which was very inefficient and costly. On a continuous basis, a dedicated operator had to bias each heliostat one at a time on the BCS target by looking at a thermal image or video image of the target on a computer screen and adjusting the image's position (up-down-right-left). Often another field 
person had to identify the heliostat being aimed and communicate with the control room by walkie-talkie.

Solution: A fully-automated system should be utilized that is capable of evaluating and biasing four heliostats at a time (one in each quadrant). As an option, multiple heliostats in each quadrant could be evaluated and biased simultaneously, if desired, by locating at least two aim points on each BCS target face.

\subsection{Inlet and Outlet Vessel Level Instrument}

Problem: The bubbler-type level instrument used in Solar Two did not function adequately in the pressurized inlet vessel during periods of rapid pressurization or depressurization. In addition, it required a significant amount of expensive instrument quality air to operate. Bubbler performance in the low-pressure outlet vessel was satisfactory.

Solution: The inlet vessel bubbler system was replaced by a radiation level system that was tested at Solar Two and performed nominally. This latter, non-intrusive system would be the reference design for both vessels. Sufficient radiation source strength must be present for the radiation level system to function properly.

\subsection{Thermocouple Failures and the Use of IR Technology to Determine Tube Wall Temperatures}

Problem: Using hundreds of thermocouples spot-welded to the back of the receiver tubes was costly to fabricate and install. During repeated heatup and cooldown, some thermocouples leads failed due to repeated bending. Those thermocouples examined did not experience mechanical separation from the tube wall. This failure was evidently caused by the thermal growth of the tubes and the friction of the thermocouple leads as they passed through the panel insulation.

Solution: The limited use of a portable IR camera was successful at Solar Two in searching for cold/hot spots during preheat and fill.

Three or four IR cameras should be permanently located in the heliostat field and directed at the receiver surface. As an option, mounting the cameras on the receiver deck should be evaluated.

Thermocouples that are tack-welded to the back of tubes should have flexible leads with enough slack so that tube movement caused by thermal growth would not break the thermocouple-totube-welds joints.

\subsection{Molten Salt Pressure Sensors}

Problem: High-temperature, direct-impedance, variation-type pressure sensors are very expensive, inaccurate, and easily damaged. Several were inadvertently damaged during 
construction when workmen accidentally stepped on the leads. An attempt to reweld the leads failed because of their delicate nature.

Solution: Investigate the use of NaK-filled or other type pressure transducers. Physically protect the metallic and flexible leads of the sensor by structural steel, as was ultimately added in Solar Two. Provide redundant inlet pressure sensors and do not provide outlet pressure sensors since the receiver outlet is near atmospheric pressure. 


\subsection{Receiver System Operation}

\subsection{Precautions Against Explosion}

Problem: Using of high-pressure air compressors to pressurize the receiver inlet vessel introduces the potential for an explosion in the inlet vessel. In the event of a filter failure or lack of preventative maintenance, compressor oil can carry over to the inlet vessel, which already contains a strong oxidizer (molten salt and air) and high temperature $\left(290^{\circ} \mathrm{C}\right)$. Since this temperature is above the flash point of most light oils, the potential for auto-ignition exists.

Solution: The use of redundant filters and a rigorous maintenance schedule should be considered. Oil-free air though a source like air bottles should also be considered, although this would be significantly more expensive over the life of the plant.

\subsection{Air Accumulator for Inlet Vessel}

Problem: An air compressor and accumulator system was used at Solar Two to aid the pressurization of the inlet vessel following a loss of pumped flow event. Its function was to help move salt through the receiver for about one minute to prevent overheating of the tubes until the heliostats could be automatically defocused. This system resulted in a potentially too rapid flow through the receiver and expulsion of the inlet vessel inventory before the heliostats could be defocused. The addition of an active throttling valve would be required and is a system complication. The compressor and accumulator system was deemed an unnecessary addition to the pressurized air already available in the "closed" inlet vessel.

Solution: Do not provide a separate air compressor and accumulator. Analysis and tests at Solar Two showed that the inlet vessel alone was sized to provide sufficient decaying pressurized salt and air to protect the receiver in the event of a loss in pumped flow.

\subsection{Potential For Chloride Stress Corrosion Cracking}

Problem: The potential for chloride stress corrosion cracking (CSCC) in stainless steel was identified by Rocketdyne before the initiation of Solar Two. It was pointed out that as long as the key conditions were present, CSCC could occur anywhere on the metal surface. The stainless-steel receiver tubes and some stainless-steel piping on the ground experienced CSCC originating on the inside. A dry air purge was installed and effectively stopped further CSCC from occurring in the receiver by driving off moisture when the system was cool.

Solution: An "advanced" receiver tube material that is essentially immune to CSCC should be utilized in the next receiver. Stainless-steel piping, however, might still be used for high temperature service in the salt system. Because the receiver is open to the atmosphere, when it cools at night it "breathes" and can collect condensation (water) from the air. This condensation can then flow to other parts of the system. An active, positive-pressure, dry air purge could be 
used to preclude condensation on interior piping and component surfaces. Like Solar Two's original requirement, trickle trace heat would be applied to all piping and components when molten salt is not present to further preclude condensation. The cost to provide trickle heat to maintain pipe and component temperatures above the dew point is minimal. Positive-pressure dry air and trickle heat should both be used because trickle heat may not protect all the receiver tubes. However, a detailed evaluation should be made to determine which portions of the system would be protected by each of these methods.

\subsection{Thawing Frozen Panels}

Problem: Occasionally, frozen salt would prevent fill of one or more tubes or even panels. This was noted by IR cameras located in the field and directed toward the absorber surface during dry preheat and flood fill.

Solution: The existence of a frozen section is indicated by the IR camera as a "cold" region on the receiver surface. Upon such an indication, the receiver was drained of liquid salt and the drain and vent valves were left opened. Solar Two was successful in thawing the frozen region. First, upper and lower ovens were confirmed to be heated to at least $260^{\circ} \mathrm{C}\left(500^{\circ} \mathrm{F}\right)$ for at least 15 minutes. Then preheat heliostats were focused on the lower free surface of the panel and additional heliostats were slowly added along the panel's upward vertical length. The IR camera would confirm the thaw as the frozen salt melted. This method should be used for follow-on plants.

\subsection{Receiver Control Algorithm}

Problem: Flow rates through each of the two receiver circuits was controlled to produce a constant outlet temperature of $565 \pm 14^{\circ} \mathrm{C}\left(1050 \pm 25^{\circ} \mathrm{F}\right)$ under varying solar flux conditions. In order to achieve this, the pump speed was varied to provide the desired inlet vessel pressure (and subsequently flow rate) for the time of day and day of year. Fine flow control (trim) was accomplished by throttling flow control valves at the inlet to each of the two circuits. Three signals were utilized in the algorithm, including feed forward incident flux, feed back from average back-of-the-wall tube temperature, and feed back from receiver outlet temperature. Finally, photometers were provided for feed forward signals and used to indicate the presence of a cloud. The photometers signaled the salt flow to ramp up to a predetermined clear sky value in anticipation of cloud clearance. This algorithm was unnecessarily complicated by the potential for several competing signals (that were proportionally weighted) to be in conflict.

Solution: A simpler algorithm that usually controlled outlet temperature on receiver outlet temperature signal was adopted. Flux signals for normal flow rate were not utilized. Pump speed and flow control valves still controlled receiver outlet temperature based upon the outlet temperature signal. The tube back-wall temperature signal was then used to remove heliostats from the overheated panels. Photometer signals were still utilized to send the receiver into clearsky flow-rate in the event of clouds. 


\subsection{Panel Fabrication}

\subsection{Panel Assembly Facility}

Problem: The panel assembly facility was too small and the assembly process required several buildings. This reduced efficiency because of the distances the panels had to travel.

Solution: Provide a large enough facility with sufficient vertical height to accommodate all the assembly operations. Provide power hand trucks so that a receiver panel could be moved by only two persons.

\subsection{Panel Assembly Processes and Material Flow}

Problem: Not all processes were strictly adhered to during the assembly phase. For example, tube-to-clip welding was modified from its original plan so that a chill block was notused. Assembly facility layout was not conducive to efficient flow of materials because a panel often had to be moved great distances between assembly steps.

Solution: Process development personnel should train assembly personnel and periodically monitor the assembly operation to assure that the process is understood and consistently followed. A larger facility, as identified in Section 5.2, will aid the flow of materials during the assembly operation. A careful time and material flow layout and evaluation should be performed prior to the facility layout.

\subsection{Paint Curing}

Problem: The paint curing process takes time (about $24 \mathrm{hrs}$ per panel) and requires significant capital expenditure (about $\$ 50,000$ for Solar Two) for a curing oven.

Solution: Paint curing with an oven worked well at Solar Two. An evaluation of paint curing in place, with heliostats on the receiver, should be performed because such paint curing will probably be required at some time in the receiver life. Uncured paint on new panels presents an additional handling problem, since uncured paint is more likely to be damaged (scratched) during handling operations.

\subsection{Manufacturing Tooling}

Problem: Adequate tooling must be provided for more efficient assembly of the receiver panels. Tooling for Solar Two was minimized because of the one-time experimental nature of the program. Receiver panel assembly time was increased because of the minimum tooling used. 
Solution: Provide high-quality production tooling and fixtures, including: 1) clip-to-tube semiautomated arc welding stations (three to five); 2) header holding fixtures (four sets); 3) tube clamps for header-to-tube circumferential welding (eight sets); 4) at least five circumferential inplace weld machines; 5) tube clamps for tube-to-tube circumferential welding (eight sets); 6) overhead crane coverage; 7) mobile panel handling fixtures with flip-over capability (one fixture for each panel would be ideal); and 8) handpower movers and forklifts to move the panel handling fixtures.

\subsection{Tube Support Clips}

Problem: Stamped clips from rolled material maintain some of the curvature of the rolled stock and are often not straight. This may affect efficiency and quality of the clip-to-tube weld.

Solution: Work with the supplier to assure an acceptably straight product is provided. The supplier should debur and clean the finished product to the required specifications in preparation for welding.

\subsection{Insulation Modules}

Problem: Insulation modules are relatively expensive to fabricate. Warping of the back plates can occur when welding supports.

Solution: Try to standardize the various types of insulation modules to simplify their fabrication and reduce costs. Weld designs must minimize heat input and consider the potential for backplate warping. 


\subsection{Site Construction}

\subsection{Tower Elevator}

Problem: The Solar Two elevator was unreliable, too slow, and too small, significantly impacting construction efficiency. Follow-on receiver towers may be significantly taller, exacerbating the problem.

Solution: Provide a faster-speed elevator with sufficient capacity to be used for personnel and equipment. Provide rest rooms in the tower to reduce the number of worker trips to the ground.

\subsection{Construction Contractor Procurements}

Problem: Boeing purchased many receiver system components that could have been procured by the construction contractor.

Solution: Allow components like piping, hangars and supports, structural steel, conduits, insulation, decks and ladders, heat trace, etc., to be procured by the construction contractor to the specifications. This shift would allow a cleaner interface, since the construction contractor would be responsible for timely delivery to maintain schedule and would be responsible for part control.

\subsection{Weather Delays During Construction}

Problem: Over a 30-day period, wind was sufficiently low only nine days for receiver panels to be lifted and set on the tower. At other times, welding was delayed due to windy conditions.

Solution: Provide an adequate schedule margin (at least a factor of three) to accommodate the weather. Wind speed significantly increases with tower height. If possible, select a time of year to lift panels when winds are calm. Wind as low as $15 \mathrm{~km} / \mathrm{hr}(10 \mathrm{mph})$ can preclude a panel lift. Provide a portable tent structure to minimize wind during welding.

\subsection{Construction Work Shifts}

Problem: Working 10 hours/day, 6 days/week quickly became counterproductive after about a month and was not effective in making up large schedule slips. It also increased the potential for accidents due to tired workers. Using more workers was difficult because of the limited space in the receiver system.

Solution: Carefully plan the construction schedule and use extended work weeks sparingly. Consider day shifts with different workers to maintain high efficiency. Be aware that work at night can be more hazardous and less efficient. 


\subsection{Management}

\subsection{Solar Plant Engineering Responsibility}

Problem: The system responsibility, or interface, was not "drawn" optimally in Solar Two. This led to some problems at the physical interfaces and heat flux interfaces. The downcomer pipe did not match and a jog had to be incorporated, and thermal expansion of the downcomer was not adequately accommodated and some receiver panels were over-fluxed.

Solution: The most efficient interface is for the same supplier to provide the receiver system above the deck, the riser pipe from the cold pump and downcomer piping to the hot tank, the tower above the deck, possibly the tower below the deck, the heliostat field layout, and the solar control system (heliostats and receiver). The solar control system must be designed with the control room and balance of plant integrator.

\subsection{Collocation of Functions}

Problem: Physical separation of project functions hindered communication and increased project schedules and costs. It also added travel time and was an inconvenience.

Solution: Collocation of management, engineering, QA, contracts, business management, procurement, and manufacturing would increase efficiency. Construction and manufacturing personnel should work with engineering from the start and throughout the project to maximize the receiver system fabrication process. 


\section{Appendix A: Solar Two Receiver Advanced Panel (W2) Final Inspection}

\section{A.1 Purpose}

This appendix documents the condition of the Solar Two advanced receiver panel (designated W2) after removal and shipment to the Boeing Santa Susana Field Laboratory. A visual inspection and evaluation of the panel was performed to determine its condition after operation at Solar Two. Special attention was given to the condition of the high absorptivity tube surface, tube straightness under thermal stress, the appearance of salt leaks, the condition of the thermal insulation, the proper functioning of the tube support clips, and the interior of the panel just inside the headers. It was important to inspect the panel to identify any off-normal trend or condition that might adversely affect its operation over a 30-year life in a commercial plant. Photographs were taken to document the overall appearance of the panel.

\section{A.2 Background}

Molten salt was first introduced into the Solar Two receiver on February 28, 1996. In January 1998, an original 316 stainless-steel receiver panel (W2) was replaced with an advanced highnickel alloy receiver panel. The advanced receiver panel was in operation and remained in place until the Solar Two plant was shut down on April 8, 1999. With the advanced panel in place, Solar Two generated over 7,000 MWe-hrs of electrical power.

In position, the advanced panel was located 30 degrees west of true north. In this position, it was exposed to a maximum concentrated solar flux of $750 \mathrm{~kW} / \mathrm{m}^{2}$. Maximum peak molten salt temperature during steady-state full power operation was about $400^{\circ} \mathrm{C}\left(750^{\circ} \mathrm{F}\right)$. Nominal peak operating temperature was about $345^{\circ} \mathrm{C}\left(650^{\circ} \mathrm{F}\right)$. Position $\mathrm{W} 2$ was chosen because it exposed the advanced panel to some of the highest solar flux. Salt flow through the advanced panel was in the upward direction. The salt coolant used in Solar Two was a mixture of $60 \%$ sodium nitrate and $40 \%$ potassium nitrate.

The advanced receiver panel was removed from Solar Two on March 23, 2001 and inspected on March 30, 2001.

\section{A.3 Inspection Results}

1. The overall appearance of the advanced panel was excellent (see Figure A-1).

2. As received, the panel was missing tubes number 1 and 16 (tubes numbered 1 through 32 starting from the right side when viewing the front of the panel in its correct vertical position). Sandia National Laboratories had previously removed these tubes. 


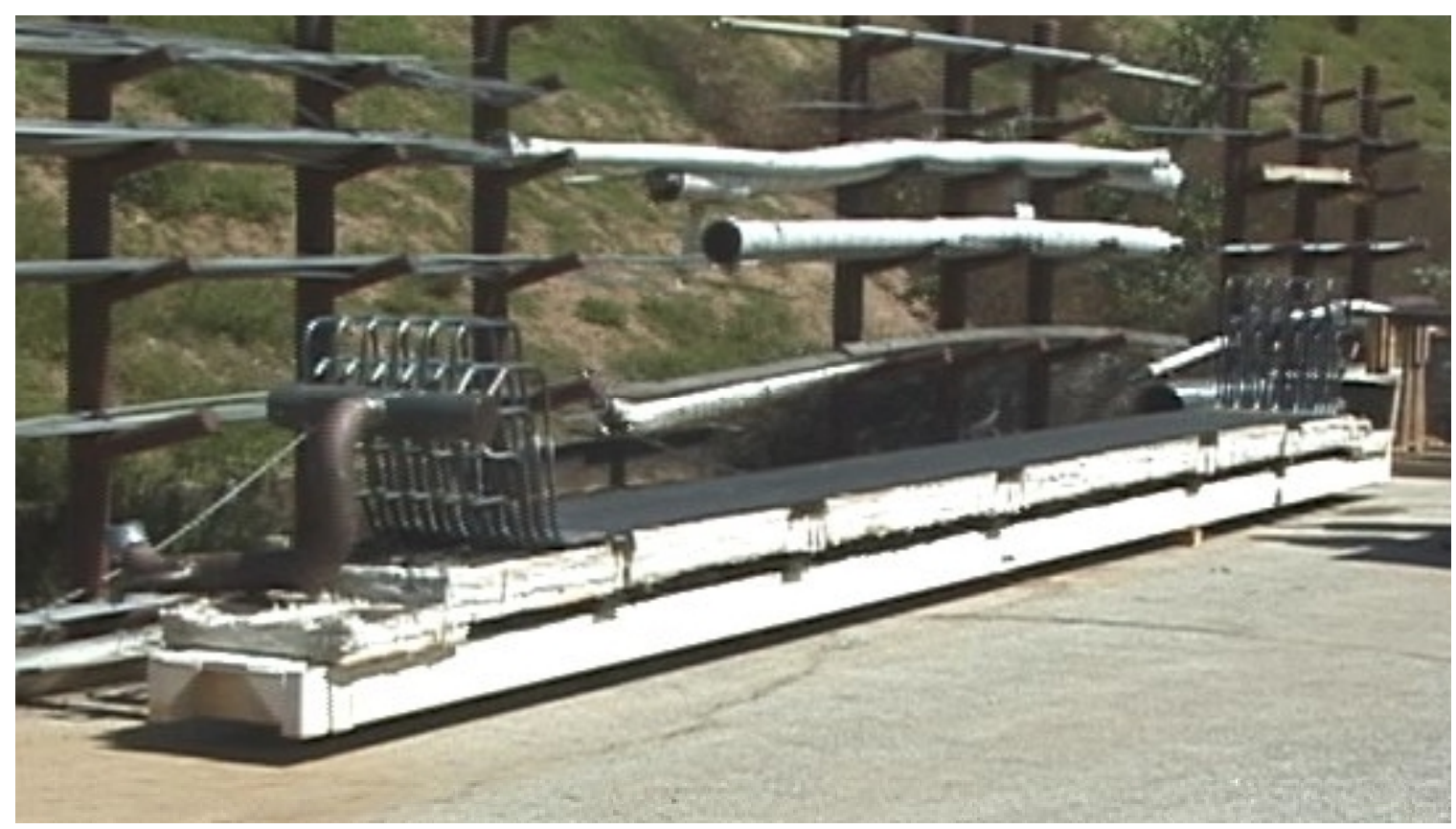

Figure A-1. Overall Panel

3. Inspection of the inside of both the upper and lower header's 10-cm (4-inch) (outlet/inlet) pipes showed no trace of coolant salt residue within the panel.

4. A shipping lock was in place to assure there was no relative movement between the tubes and the strong back.

5. The top and bottom headers had single thermocouples rigidly attached. All spot-welded stainless-steel tabs used to secure the thermocouples were still in place (see Figure A-2).

6. All tube thermocouples were still rigidly attached to the tubes.

7. There were no observed salt leaks in the headers or the tubes, including weld regions.

8. The general appearance of the panel tubing was excellent, with no sign of thermal distortion. Tubes were straight with no waviness in any direction. There was no indication of bowing or out-of-plane distortion due to thermal stress (see Figure A-3).

9. There were no observed dings or dents in the tubing (see Figure A-3).

10. The high-absorptivity, black Pyromark (1200 series) absorber tube surface was in excellent condition with no signs of chips or significant scratches (see Figure A-3).

11. Good adherence of the high-absorptivity Pyromark paint was observed. Duct tape placed on six random locations along various tube surfaces failed to remove any Pyromark paint when it was pulled off. 


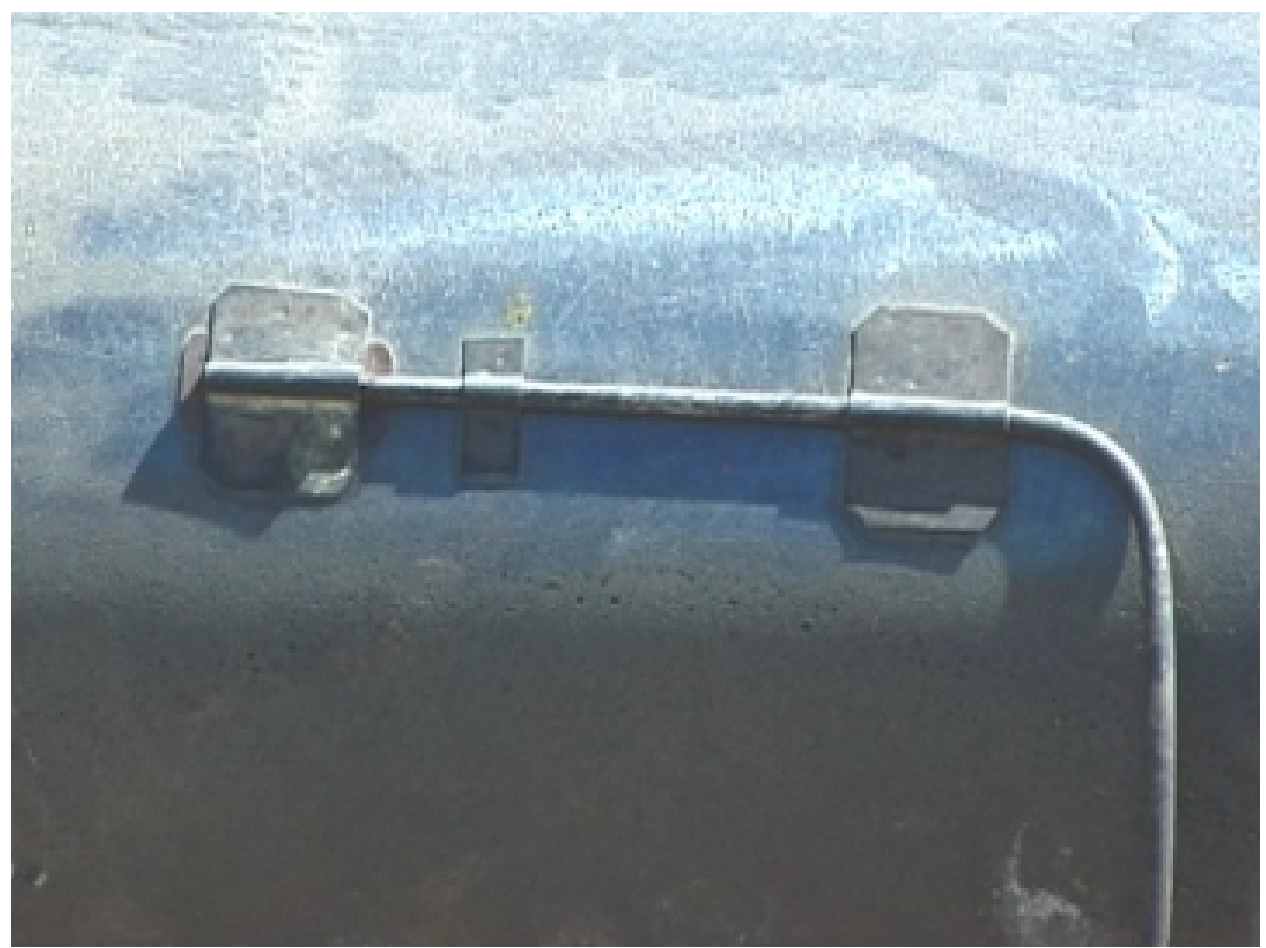

Figure A-2. Header Thermocouple Attachment

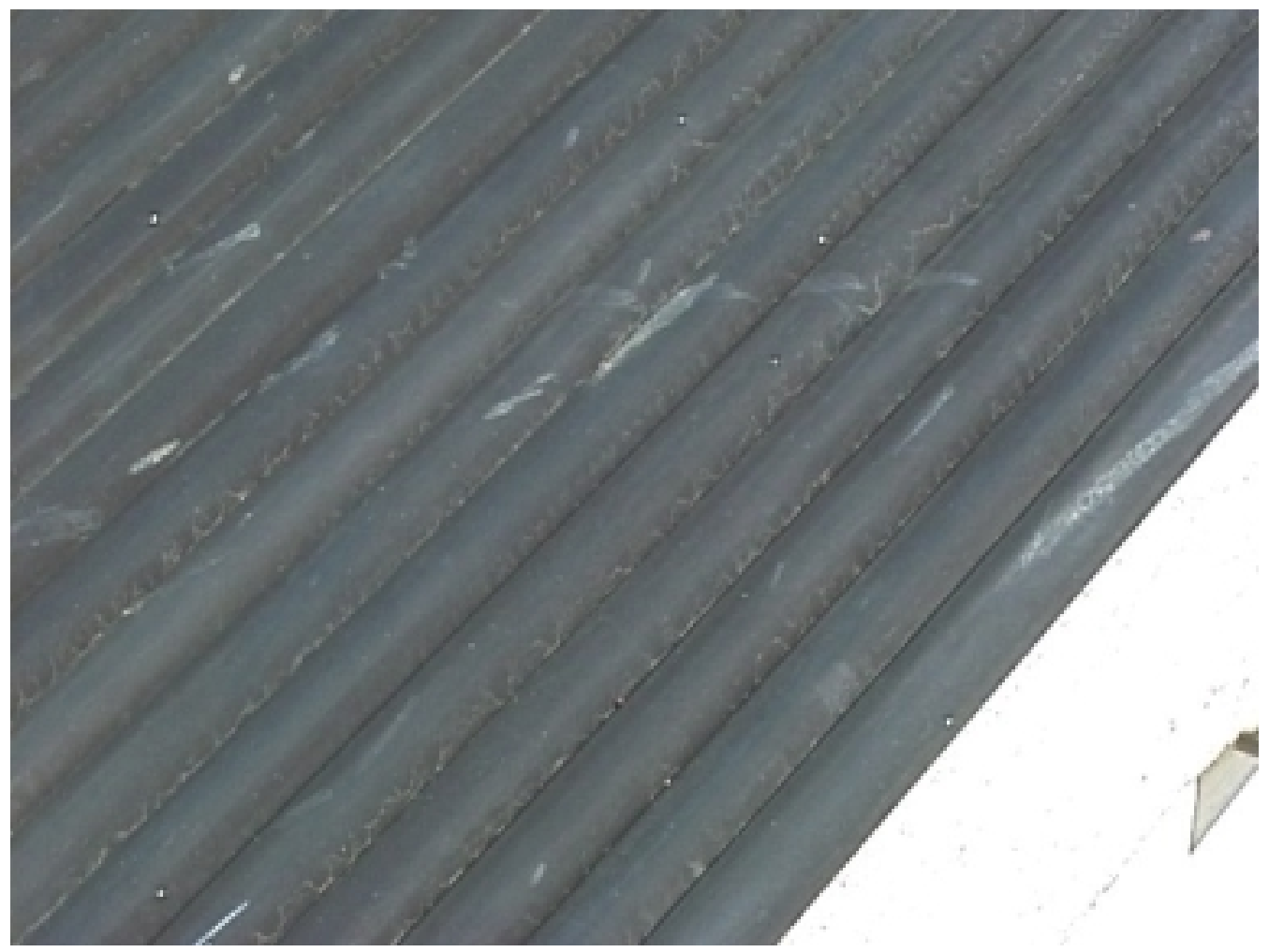

Figure A-3. Receiver Tube Close Up Photograph 
12. Although an absorptivity measurement was not performed, the surface condition and flat black color showed little visual reflection and it is estimated (from experience with previous measurements) that absorptivity was about 0.95-0.96. This is considered excellent. Newly-painted panels previously had absorptivity readings as high as 0.97-0.98.

13. Panel oven electrical heaters appeared to be in excellent condition with no discoloration that might indicate over heating, corrosion, or contact with salt. See Figure A-4.

14. The strongback was straight and paint appeared excellent with no burns that would indicate overheating (see Figure A-1).

15. The stainless-steel support guides appeared in good condition with no indication of overheating. The nitronic rods on the support guides that contact the sliding tube clips showed no wear.

16. All tube clips were engaged to the nitronic guide rods; no clips were sprung. Clips that were inspected showed no wear.

17. All clips were attached firmly to their tubes.

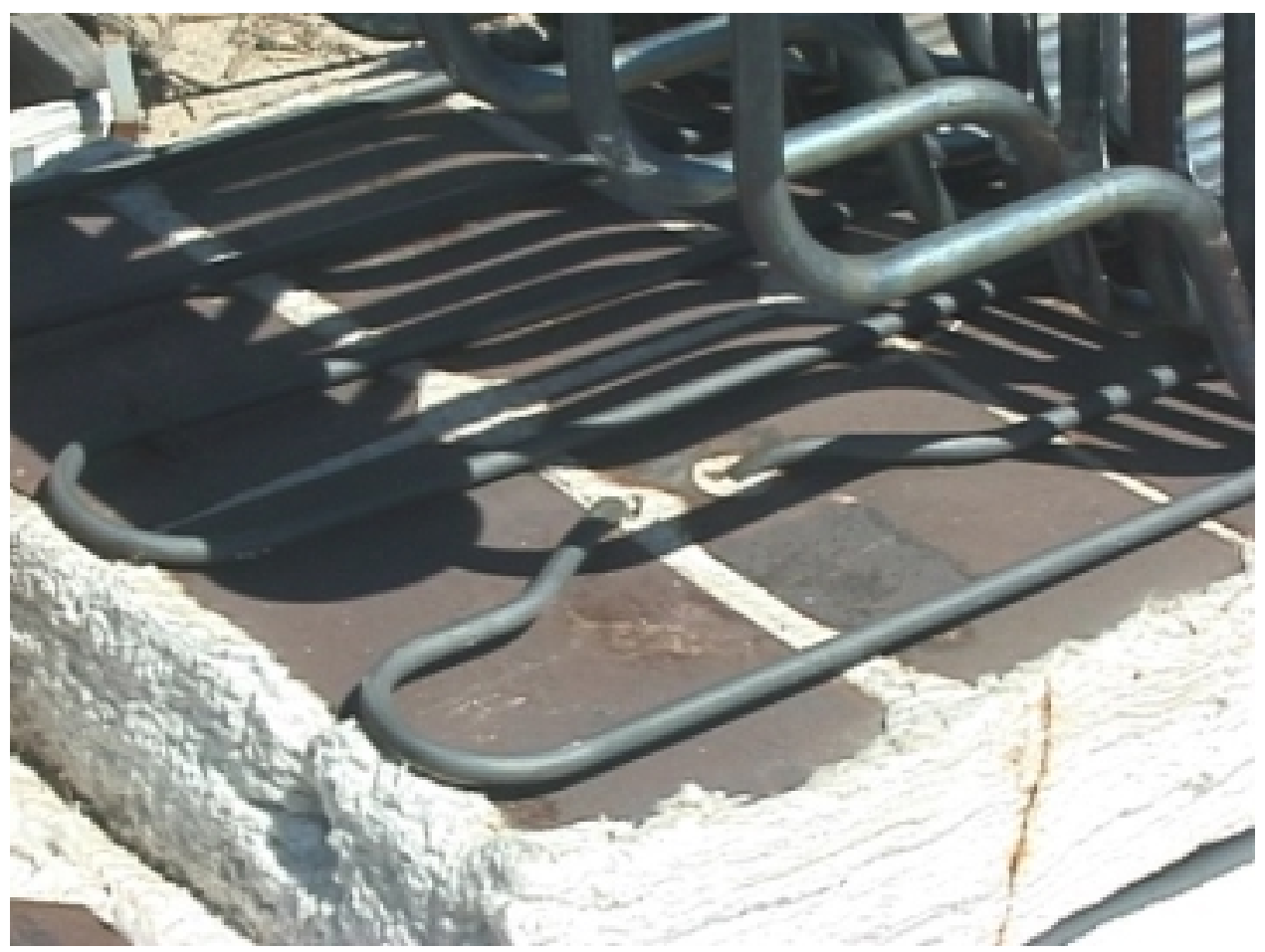

Figure A-4. Panel Electrical Heaters 
18. Insulation appeared excellent and in place with no shifting of position; see Figures A-1 and A-4. Insulation under the bottom of the tubes wascompressed. There was still an elastic quality to the insulation with minimum set. This resulted in no gaps between the insulation and tubes. No observable tube wear from insulation contact was noted.

19. Insulation wrapped around the guide supports was still firmly in place.

20. Electrical insulated wire and connectors on the back of the panel were in good condition.

21. Tube bends between headers and the straight absorber section of the tubes appeared to be in excellent condition with no observed deformities.

22. Headers appeared straight and in excellent condition.

23. Stainless-steel sheet metal plates used to hold upper and lower insulation modules were straight and in good condition with no observable warpage (see Figure A-4).

24. Inspection of one upper and one lower header oven cover indicated severe temperatures that scorched the high reflectivity white Pyromark (2500 series) paint finish and caused some minor stainless-steel distortion. See Figure A-5. Even so, the general configuration of the oven covers was good with welds and attachments secure and insulation in place.

\section{A.4 Removal of Panel W-2 from Solar Two}

Boeing personnel met with University Marelich Mechanical Contractors on Tuesday, March 20, 2001 to initiate preparations for removing solar receiver panel W-2. The contractor had an extendible boom forklift and a basket-type man-lift delivered to the site in support of the panel removal. The facility was toured and the locations of electrical circuit breakers for lighting and crane power were determined. Crane power supply circuit breakers were found and were tripped back to the main power distribution panel. All breakers were reset and the crane was verified as operational.

The crane service and certification company representative arrived to check out and certify the five-ton jib crane at the top of the solar tower. Prolonged operation of the crane in the down mode caused the circuit breakers to trip again. The problem was found to be in the direction control contactors. The contactor assembly was removed, cleaned, lubricated, and reinstalled. Additional check-outs revealed that the limit switch that prevents the hook from going too high or too low was not functional and replacement parts were ordered.

In preparation for panel removal, the panels adjacent to W2 were moved away using existing jacking screws. The lower header assembly was cut from the adjacent panel assembly 


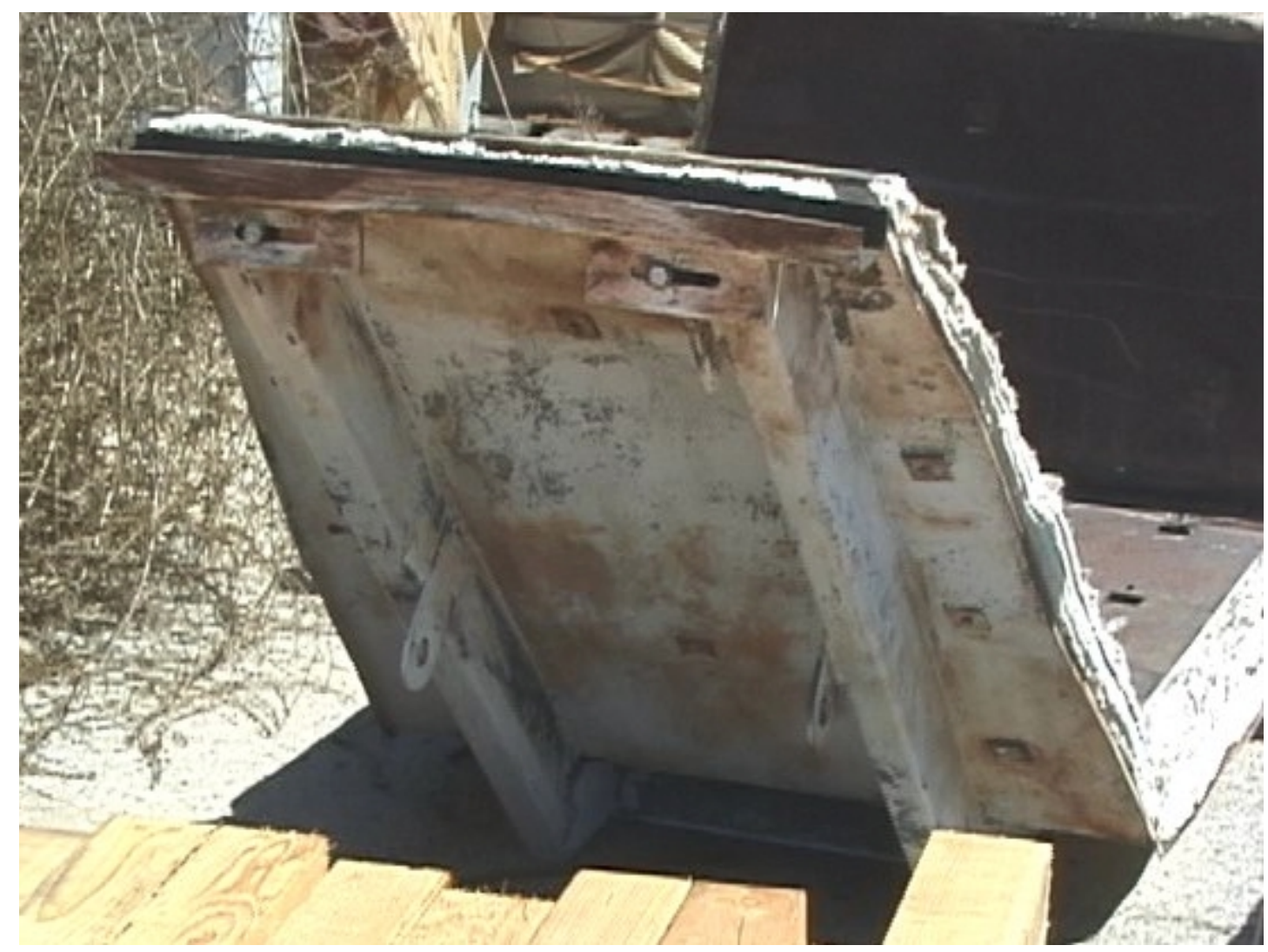

Figure A-5. Header Oven Cover

with a portable band saw. With the limited access to the lower header, a high-speed, abrasive blade grinding tool would have made cutting more efficient. The portable band saw did the job; however, the process consumed most of the saw blades available. Cutting of the top header assembly could not be accomplished with the caged man-lift because the crane was not yet operational. An extension ladder was lowered to the oven assembly on the adjacent panel and thoroughly secured to the platform above. A pipe fitter then descended the ladder, utilizing a double lanyard and full body harness fall protection system. The portable band saw was secured to a rope and lowered, and the upper header was successfully severed from the adjacent panel assembly. Eyebolts, shackles, and nylon slings were secured to existing threaded lifting points, and slings were secured with rope for rigging to the crane when it became available.

Spare tube assemblies and a set of top and bottom oven enclosures were accumulated for shipment with the panel assembly. Wooden shipping supports were located in the Solar Two storage area and used to minimize deflection of tube manifolds during transport.

Upon arrival of crane repair parts, repairs and final checkout required two service technicians approximately five hours. The crane was then certified (proof load tested) by means of a waterfilled bag and weight indication device. A total of $5700 \mathrm{~kg}$ (12,500 pounds) of water were suspended from the crane for 15 minutes. Certification was documented and the crane was released for regular service. A significant and steady wind from the west jeopardized the ability 
to perform the final lift safely. It was decided to initiate final lifting at first light the following morning.

A safety briefing with the lift crew was held at 6:00 am and the lift was initiated at 6:30. The panel assembly was placed in a horizontal position and ready for shipment by 7:10 am. Trucking arrived, as scheduled, at 8:00 and the panel with spare accessories were loaded and secured to the truck bed. The truck left for Rocketdyne, Santa Susana Field Laboratory at 9:00 am. The Solar Two facility was then secured, power for lighting and the crane was turned off, and all doors and gates locked. The crew then departed for their next assignment.

\section{A.5 Summary}

The Solar Two receiver advanced panel (W2) was removed from the receiver tower and delivered to Boeing. A visual inspection of the advanced panel, which had been in use for over 15 months, showed no indication of warping, leaking, impact damage, or any other off-normal conditions, including swelling from freezing and thawing. Precise measurements that would be needed to confirm small dimensional changes, such as small amounts of swelling, were not performed. The advanced panel appears to have performed exceptionally well during its period of operation in Solar Two. 
UNLIMITED DISTRIBUTION:

Mr. Donald Aitken

Union of Concerned Scientists

2625 Alcatraz Ave., \#505

Berkeley, CA 94705-2702

Dr. Daniel J. Alpert

Senator Bingaman's Office

SH 703, 2nd \& Constitution

Washington, DC 20510

Mr. Ian Andrews

PacifiCorp

Utah Power Generation Engineering

1407 West North Temple

Salt Lake City, UT 84140-0001

Robert M. Balzar

Nevada Power \& Sierra Pacific

Power

6226 W. Sahara Ave.

Las Vegas, NV 89151

Daniel L. Barth

Nagle Pumps, Inc.

1249 Center Avenue

Chicago Heights, IL 60411

Mr. Bud Beebe

Sacramento Municipal Utility

District

6201 'S' St.

P.O. Box 15830

Sacramento, CA 95852-1830

Jose Benevente Sierra

Avda. del Puerto N 1-6

11006 Cadiz

Spain

Jerry Berquist

Southern California Edison Co.

300 N. Lone Hill Avenue

San Dimas, CA 91773
Manuel J.Blanco Muriel

CIEMAT - PSA

Apartado 22

E-04200 Tabernas (Almeria)

Spain

Dan Brake, P.E.

FPL Energy, Inc.

6952 Preston Avenue

Livermore, CA 94550

Mr. Robert A. Briffett

Los Angeles Dept. of Water and

Power

P.O. Box 111, Room 1129

Los Angeles, CA 90051-0100

Gary D. Burch

U. S. Department of Energy EE-16 1000 Independence Avenue SW

Washington, DC 20585

Mr. Barry L. Butler

Science Applications International Corp.

Room 2043, M/S C2J

10260 Campus Point Dr.

San Diego, CA 92121

Mr. John Carstensen

Idaho Power

$1221 \mathrm{~W}$. Idaho

MS CHQ-4

Boise, ID 83702

Mr. Gilbert E. Cohen

Duke Solar

2101 - 115 Westinghouse Blvd.

Raleigh, NC 27604

Walter E. Collier

Boeing Company

499 Boeing Blvd., MC JW-63

P.O. Box 240002

Huntsville, AL 35824-6402 
David L. Dean

Boeing Company

499 Boeing Blvd.

PO Box 240002

Huntsville, AL 35824-6402

John C. Dewey

Pitt-Des Moines, Inc.

9719 Lincoln Village Drive, Suite 301

Sacramento, CA 95827

David Engberg

PacifiCorp

825 NE Multnomah

Portland, OR 97232

E. A. Fletcher

University of Minnesota

1111 Church Street, SE

Dept. of Mech. Engr.

Minneapolis, MN 55455

Scott D. Frier

KJC Operating Company

41100 Highway 395

Boron, CA 93516-2109

Bobi Garrett

National Renewable Energy

Laboratory

1617 Cole Blvd.

Golden, CO 80401-3393

Mr. Ranji George

South Coast AQMD

21865 Copley Drive

Diamond Bar, CA 91765

Mr. Dave Gorman

Advanced Thermal Systems, Inc.

5031 W. Red Rock Drive

Larkspur, CO 80118
Mr. William R. Gould, Jr.

Nexant

44 Montgomery St., Suite 4100

San Francisco, CA 94104-4814

Mr. Tom M. Griffin

Boeing Company

P.O. Box 582808

Tulsa, OK 74158

Ignacio Grimaldi Pastoril

Ghersa

Avda. del Puerto N 1-6

11006 Cadiz

Spain

Pedro Grimaldi Pedrosa

Avda. del Puerto N 1-6

11006 Cadiz

Spain

Mr. Jose Gutierrez

Los Angeles Dept. of Water and Power

111 North Hope Street, Room 648

Los Angeles, CA 90012

Ms. Mary Jane Hale

National Renewable Energy

Laboratory

1617 Cole Blvd.

Golden, CO 80401-3393

Larry Hamlin

Southern California Edison Co.

300 N. Lone Hill Avenue

San Dimas, CA 91773

Herb Hayden

Pinnacle West Capital Corporation (APS)

400 N. Fifth Street, MS 8931

Phoenix, AZ 85004 
Mats E. Hellstrom

Queue Systems, Inc.

1800 St. Julian Place, Suite 2000

Columbia, SC 29204

Dr. Arlon Hunt

Lawrence Berkeley Laboratory

University of California

MS 90-2024

One Cyclotron Road

Berkeley, CA 94720

Mr. Gus Hutchison

Solar Kinetics, Inc.

10635 King William Drive

P.O. Box 540636

Dallas, TX 75354-0636

Micel E. Izygon, $\mathrm{PhD}$

I-Net

NASA/Johnson Space Center

Software Technology Branch - MC

BT2

NASA Rd. 1

Houston, TX 77058

Mr. Paul Jaster

3M - Solar Optics Program

3M Center, Bldg. 225-2N-06

St. Paul, MN 55144-1000

Mr. Alexander Jenkins

California Energy Commission

Energy Technology Development

Div. R\&D Office

1516 9th Street, MS-43

Sacramento, CA 95814-5512

Peter Johnston

Arizona Public Service

400 N. 5th Street

Phoenix, AZ 85072
Ron Judkoff

National Renewable Energy

Laboratory

1617 Cole Boulevard

Golden, CO 80401-3393

Mr. David W. Kearney

Kearney \& Associates

PO Box 2568

Vashon WA 98070

Mr. Bruce Kelly

Nexant

44 Montgomery St., Suite 4100

San Francisco, CA 94104-4814

Jim Kern

U. S. Department of Energy EE-11

1000 Independence Ave., SW

Washington, DC 20585

Michael J. Kiley

Boeing Company

6633 Canoga Ave. MC FA-66

P.O. Box 7922

Canoga Park, CA 91309-7922

Kurt Klunder

Klunder Consulting

4498 Larchmont Ct.

Dumfries, VA 22026

R. LeChevalier

Boeing Company

Energy Technology Engineering

Center

P.O. Box 1449

Canoga Park, CA 91304

Mr. Mark Lichtwardt

U.S. Bureau of Reclamation

Code D-8230

P.O. Box 205007

Denver, CO 80225 
$4 \quad$ Mr. Bob Litwin

Boeing Company

6633 Canoga Avenue

PO Box 7922 - Mail Code LA38

Canoga Park, CA 91309-7922

W. Marlatt

Boeing Company

Rocketdyne Division

6633 Canoga Avenue

P.O. Box 7922

Canoga Park, CA 91309-7922

Larry Matthews

New Mexico State University

Box 30001, Dept. 3449

Las Cruces, NM 88003-0001

Michael W. McDowell

Boeing Company

6633 Canoga Ave. MC T038

P.O. Box 7922

Canoga Park, CA 91309-7922

Mr. Mark Mehos

National Renewable Energy

Laboratory

1617 Cole Boulevard

Golden, CO 80401-3393

M. Merrigan

Los Alamos National Laboratory

P.O. Box 1663, MS J576

Los Alamos, NM 87545

Jan Miller

Salt River Project

1600 N. Priest St.

Tempe, AZ 85281

Mr. Doug Morris

Electric Power Research Institute

P.O. Box 10412

3412 Hillview Avenue

Palo Alto, CA 94303
Peter G. Mueller

U.S. Department of Energy

Nevada Operations Office

P.O. Box 98518

Las Vegas, NV 89193-8518

Mr. Jay Mulki

Hawaiian Electric Company

P.O. Box 2750

Honolulu, HI 96840-0001

James Nagle

Nagle Pumps, Inc.

1249 Center Avenue

Chicago Heights, IL 60411

Mr. Don Osborne

Sacramento Municipal Utility

District

6201 'S' St., P.O. Box 15830

Sacramento, CA 95852-1830

Mr. Ernie Palomino

Salt River Project

P. O. Box 52025

Mail Station ISB664

Phoenix, AZ 85072-2025

Terry Peterson

EPRI

3412 Hillview Avenue

Palo Alto, CA 94304

Lizana K. Pierce

Dept. of Energy/GFO

1617 Cole Blvd.

Golden, CO 80401-3393

Faith Puffer

Tech Reps

5000 Marble NE

Suite 222

Albuquerque, NM 87110 
Mr. James E. Rannels

U. S. Department of Energy EE-11 1000 Independence Avenue SW

Washington, DC 20585

Dale Rogers

Boeing Company

6633 Canoga Avenue

PO Box 7922 - Mail Code LA38

Canoga Park, CA 91309-7922

Manuel Romero Alvarez

CIEMAT - Madrid

Institudo de Energias Renovables

Avda. Complutense, 22

E-28040 Madrid

Spain

Tommy Rueckert

U. S. Department of Energy EE-11

1000 Independence Avenue SW

Washington DC 20585

Mr. D. A. Sanchez

U.S. Department of Energy/AL

P.O. Box 5400

Albuquerque, NM 87115

Mr. Scott Sklar

Stella Group, Ltd.

733 15th Street, NW Suite 700

Washington, D.C. 20005

Glenn Strahs

U. S. Department of Energy EE-11

1000 Independence Avenue, SW

Washington, DC 20585

Steven E. Taylor

Southern California Edison Co.

2131 Walnut Grove Ave.

Rosemead, CA 91770
Mr. Robert Thomas

Advanced Thermal Systems, Inc. 5031 W. Red Rock Drive

Larkspur CO 80118-9053

Tom Tracey

6922 S. Adams Way

Littleton, CO 80122

Dr. Lorin Vant-Hull

University of Houston

Physics Department 5506

4800 Calhoun Road

Houston, TX 77204-5506

Mr. Byron J. Washom

Spencer Management Associates

P.O. Box 724

Diablo, CA 94528-0724

Mr. Tim Wendelin

National Renewable Energy

Laboratory

1617 Cole Blvd.

Golden, CO 80401-3393

Mr. David White

Solar Kinetics, Inc.

10635 King William Drive

P.O. Box 540636

Dallas, TX 75354-0636

John White

Queue Systems, Inc.

1800 St. Julian Place, Suite 2000

Columbia, SC 29204

Mr. Bob Wichert

Sacramento Municipal Utility

District

6201 'S' St., P.O. Box 15830

Sacramento, CA 95852-1830 
Mr. Curtt N. Wilkins

U.S. Department of Energy

1309 Barnes Drive

Arlington, TX 76013

Mr. Frank (Tex) Wilkins

U. S. Department of Energy EE-11

1000 Independence Avenue, SW

Washington, DC 20585

Mr. Alex Zavoico

Nexant

44 Montgomery St., Suite 4100

San Francisco, CA 94104-4814

Sandia National Laboratories:

MS 0783 James Pacheco, 5832

MS $0131 \quad$ James Chavez, 12121

MS $0703 \quad$ Scott Jones, 6216

MS 0703 Craig Tyner, 6216

MS 0704 Marjorie Tatro, 6200

MS 0752 Earl Rush, 6218

MS 1127 Chris Cameron, 6215

MS 1127 Mike Edgar, 6215

MS 1127 Bill Kolb, 6215

MS 1127 Solar Tower Library

MS 1425 Bob Bradshaw, 8722

MS 9004 Dan Dawson, 8746

MS 9014 Scott Faas, 2271

MS $9404 \quad$ Steve Goods, 8725

1 MS 9018 Central Technical

Files, 8945-1

2 MS 0899 Technical Library,

9616

1 MS 0612 Review and Approval

Desk, 9612 